\title{
A multidimensional non-drug intervention reduced daytime sleep in nursing home residents with sleep problems
}

Alessi CA, Martin JL, Webber AP, et al. Randomized, controlled trial of a nonpharmacological intervention to improve abnormal sleep/wake patterns in nursing home residents. J Am Geriatr Soc 2005;53:803-10.

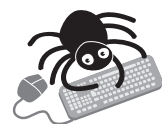

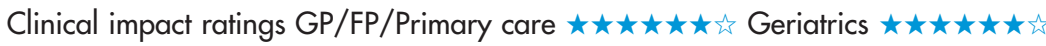

ธ

Design: randomised controlled trial.

Allocation: $\{$ unconcealed*\}†

Blinding: unblinded.*

Follow up period: 32 days for the intervention group and 16 days for the control group.

Setting: 4 community nursing homes in Los Angeles, California USA.

20 Participants: 118 residents (mean age $87 \mathrm{y}, 77 \%$ women) with daytime sleepiness and night time wakefulness. Exclusion criteria: acute illness, isolation, or being bed-bound.

$\mathbf{R}_{\mathbf{X}}$

Intervention: intervention $(n=62)$ or usual care $(n=56)$. The intervention was given over 5 consecutive days and nights. From $8 \mathrm{am}$ to $8 \mathrm{pm}$, the intervention group was encouraged to remain out of bed, received $\geqslant 30$ minutes of sunlight exposure $1 \geqslant 10000$ lux), and participated 3 times daily in a low level physical activity programme. From $8 \mathrm{pm}$ to $10 \mathrm{pm}$, residents were given a bedtime routine that included personal care, lights out, and reduced sources of noise. From $10 \mathrm{pm}$ to $6 \mathrm{am}$, efforts continued to reduce noise and light in the hallway area and rooms. Persona care was provided and timed to coincide with when residents were awake. A more detailed description of the intervention is provided on the website (www.evidence-basedmedicine.com).

Outcomes: night time sleep, night time awakenings, and daytime sleep. Secondary outcomes included participation in physical and social activities.

Patient follow up: $92 \%$ (intention to treat analysis).

*See glossary.

†Information provided by author.

\section{MAIN RESULTS}

The intervention reduced daytime sleep and the length of night time awakenings and increased participation in social and physical activities relative to usual care. Groups did not differ for night time sleep (table).

\section{CONCLUSION}

In nursing home residents with sleep problems, a multidimensional, non-pharmacological intervention reduced daytime sleep and the

For correspondence: Dr C A Alessi, Veterans Affairs Greater Los Angë Healthcare System, Los Angeles, CA, USA. cathy.alessi@med.va.gov

Sources of funding: National Institute on Aging; VA Health Services Research and Development; VA Greater Los Angeles Healthcare System Geriatric Research, Education and Clinical Center. length of night time awakenings and increased participation in social and physical activities.

\section{Commentary}

The meticulously designed and conducted study by Alessi et al shows that a fairly labour intensive, non-pharmacological intervention is successful in decreasing daytime in bed and daytime sleeping and in increasing light exposure, participation in nursing home activities, physical activity, and social conversation, but did not affect total night time sleep or number of awakenings. Only the duration of night time awakenings was modestly reduced.

Alessi et al comment on the positive implications the intervention might have had on patients' quality of life. Perhaps it would be more appropriate to speak of "quality time," as quality of life should have been defined by the study participants themselves. However, few would argue about the medical and psychosocial benefits of increased time out of bed, physical activity, and social interactions, even though the cost benefit ratio is difficult to measure. And not all the interventions studied are costly, especially those suggested for night time implementation. Minimising exposure to noise and light and provision of personal care at time of spontaneous patient awakening should be achievable with limited staff education. Individual activity costs, as suggested in the study, could be lessened by inclusion of a larger number of patients in the programmes.

The major weakness of this study is that it fails to recognise the multiple causes of insomnia. ${ }^{1}$ Even though sleep disorders are associated with advancing age and dementia, psychiatric, neurological, and medical conditions are common in this population, and interventions to manage these conditions could have had a greater effect in decreasing the sleep disruption experienced by these patients.

Claudia Beghe, MD James A Haley VA \& University of South Florida Tampa, Florida, USA

1 Diagnostic and statistical manual of mental disorders. $4^{\text {th }}$ ed. Washington, DC: American Psychiatric Association, 1994.

Intervention $v$ usual care in nursing home residents with sleep problems

\begin{tabular}{|c|c|c|c|}
\hline \multirow[b]{2}{*}{ Outcomes at 32 days } & \multicolumn{2}{|c|}{$\begin{array}{l}\text { Mean change from } \\
\text { baseline }\end{array}$} & \multirow{2}{*}{$\begin{array}{l}\text { Difference in mean } \\
\text { change from } \\
\text { baseline ( } p \text { value) }\end{array}$} \\
\hline & Intervention & Usual care & \\
\hline Daytime sleep* & $-11 \%$ & $-2 \%$ & $9 \%(p<0.001)$ \\
\hline $\begin{array}{l}\text { Night time mean } \\
\text { awakening length (min) }\end{array}$ & -0.8 & 4 & $4.8(p=0.042)$ \\
\hline Night time total sleep (h) & 0 & -0.3 & $0.3(p=0.35)$ \\
\hline $\begin{array}{l}\text { Percentage of night time } \\
\text { sleep }\end{array}$ & 0 & $-4 \%$ & $4(p=0.25)$ \\
\hline $\begin{array}{l}\text { Night time number of } \\
\text { awakenings }\end{array}$ & 2.7 & -0.9 & $3.6(p=0.34)$ \\
\hline $\begin{array}{l}\text { Participation in social } \\
\text { activities }^{*}\end{array}$ & $1.9 \%$ & $0.1 \%$ & $1.8 \%(p<0.001)$ \\
\hline $\begin{array}{l}\text { Participation in social } \\
\text { conversation* }^{*}\end{array}$ & $0.7 \%$ & $-0.4 \%$ & $1.1 \%(p=0.03)$ \\
\hline Physical activity* & $8.7 \%$ & $1.8 \%$ & $6.9 \%(p=0.001)$ \\
\hline
\end{tabular}

*Percentage of daily observations. 